\title{
PRIMARY ADENOID CYSTIC CARCINOMA MAXILLARY SINUS: A CASE REPORT
}

Shalini S. S1, Venkateswarlu V², Prasad K. R. K³, Anitha S4, L. Veena Kumari ${ }^{5}$

\section{HOW TO CITE THIS ARTICLE:}

Shalini S. S, Venkateswarlu V, Prasad K. R. K, Anitha S, L. Veena Kumari. "Primary Adenoid Cystic Carcinoma Maxillary Sinus: A Case Report". Journal of Evolution of Medical and Dental Sciences 2015; Vol. 4, Issue 55, July 09; Page: 9677-9680, DOI: 10.14260/jemds/2015/1397

ABSTRACT: Adenoid cystic carcinoma of para nasal sinuses is very rare in occurrence. Such a lesion presenting in Left maxillary sinus and extending into nose eroding orbital plate and nasal bone in a 45 year old male is presented.

KEYWORDS: adenoid cystic carcinoma, Carcinoma maxillary sinus.

INTRODUCTION: Adenoid cystic carcinoma (ACC) was first described by Robin, Lorain and Laboulbene in 2 articles published in 1853 and 1854 Primary malignant tumors of the maxilla are uncommon. ${ }^{1}$

Squamous cell carcinoma is the commonest of all tumors occuring in maxillary sinus. ${ }^{2}$ Adenoid cystic carcinoma is an uncommon malignant Tumor occurring in maxilla. Spies is the first person to use the term for the tumor as adenoid cystic carcinoma. Billroth named the tumor as cylindroma and he is the first one to observe recurrent nature of the tumor. ${ }^{3}$

CASE REPORT: A 45 years old male presented to the ENT clinic with history of a slow growing painless swelling over left cheek of 3 months duration.

Patient did not have epistaxis, anosmia, hyposmia or any nasal discharge. There is no history suggestive of difficulty in vision or lacrimation. Clinical examination revealed an ill-defined swelling on left side of face over cheek and lateral wall of nose. Nasal speculum examination showed partial narrowing of the left nasal cavity by a projecting tumor. There is no nasal septal deviation. Nasal enodoscopy showed ill-defined firm mass in left nasal cavity pushing middle and inferior turbinates medially and bleeding on touch. The mass was soft in consistency, smooth surface with no bony region underneath.

Baseline laboratory data were within normal limits. CT scan showed a soft tissue mass arising from Left maxillary antrum extending into the left nasal cavity with erosion of medial wall of maxillary sinus \& inferior wall of orbit and lateral nasal bone. (Fig. 1)

General examination showed normally functioning vital organs and no palpable lymphnodes. The eyes and auditory system were within normal limits. A provisional diagnosis of malignant tumor of left maxillary antrum was made and Endoscopic biopsy was done.

The biopsy material was processed by routine formalin fixation, paraffin embedding and $\mathrm{H}$ \& E staining. Multiple serial sections studied show a malignant tumor with cells arranged in lobular, glandular and pseudoglandular pattern (Cylindrical arrangement) with central cystic spaces and infiltrating peripherally located fibrous stroma. Tumor cells are oval to round with scant to moderate cystoplasm and mild pleomorphic vesicular nuclei. Mitosis are occasional. Cystic spaces showed ABPAS stain positive material.

The histologic features prompted us to make a diagnosis of Adenoid cystic carcinoma-tubular type, Grade 1-2. 
As the tumor has infiltrated orbital plate and nasal bone we have decided to do wide excision of tumor with neck dissection followed by radiotherapy to verify the recurrence of tumor because the literature is inept in definite treatment protocol for adenoid cystic carcinoma due to variable opinions of efficacy of only surgery in adenoid cystic carcinoma. $4,5,6,7$

DISCUSSION: Adenoid cystic carcinoma is an uncommon tumor in paranasal sinuses. ${ }^{4,8}$ The commonest type of paranasal sinus tumor is squamous cell carcinoma.

Adenoid cystic carcinoma is peculiar in its slow growth and presence of neural invasion and metastatses at the time of its first presentation. The tumor is histologically typed into cribriform, tubular and solid types. There is difference in prognosis depending on the histologic pattern from Cribriform to Tubular to solid growth pattern with solid variet associated with worse prognosis. ${ }^{6}$

Szanto et al., graded the tumor as grade I (cribriform or tubular), grade II, $<30 \%$ Solid and grade III $>30 \%$ solid growth. ${ }^{9}$ The paradox is that adenoid cystic carcinoma has less local lymphnode Metastasis, while the distant metastatses to lungs and bones are more frequent. 8

It has been reported that ACC of the nasal cavity and paranasal sinuses has a Worse prognosis than in any other area of the head and neck region. 4,5

The treatment of adenoid cystic carcinoma is preferably surgery but multiple Local recurrences are the rule. All patients treated with either surgery alone or radiation alone experienced one or more local recurrences, whereas patients who received planned combined surgery and radiation had a much lower local recurrence rate $(40 \%))^{3}$

5-year survival rates are optimistically high, but 10- to 20-year survival rates are dismally low. ${ }^{10}$ The overall survival and disease-free survival rates at 10 years were $37.6 \%$ and $13.6 \%$ respectively. Location of primary tumor, tumor stage, and histological grade were of no value in predicting a favorable survival.

In view of the controversies over the prognosis studies based on larger number of patients is necessary.

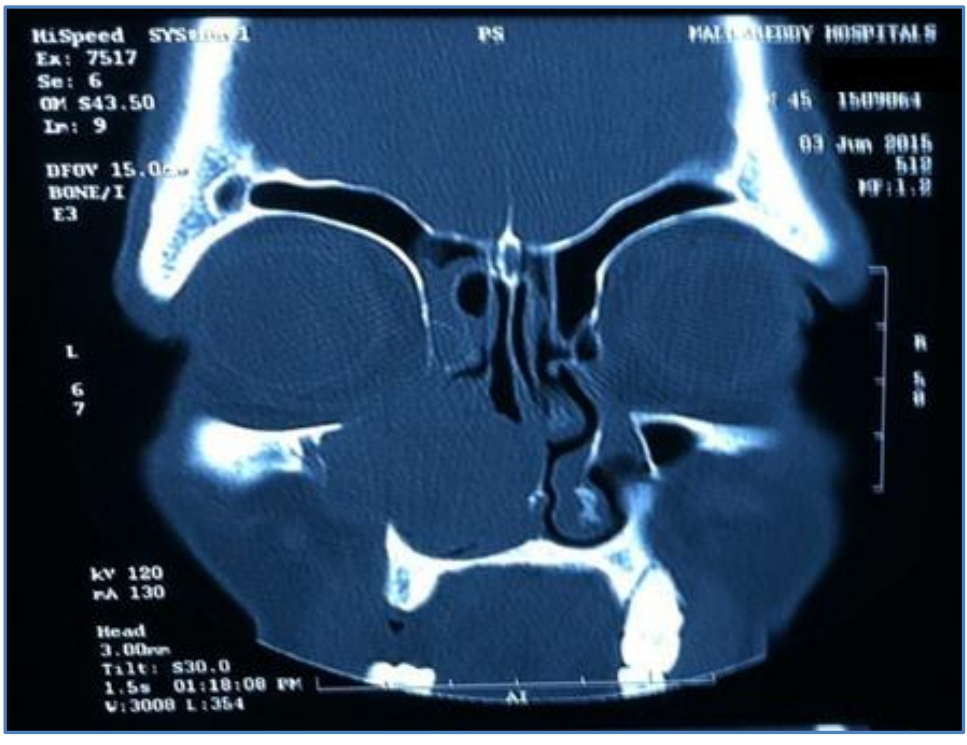

Fig. 1: CT scan shows tumor in maxillary antrum 


\section{CASE REPORT}

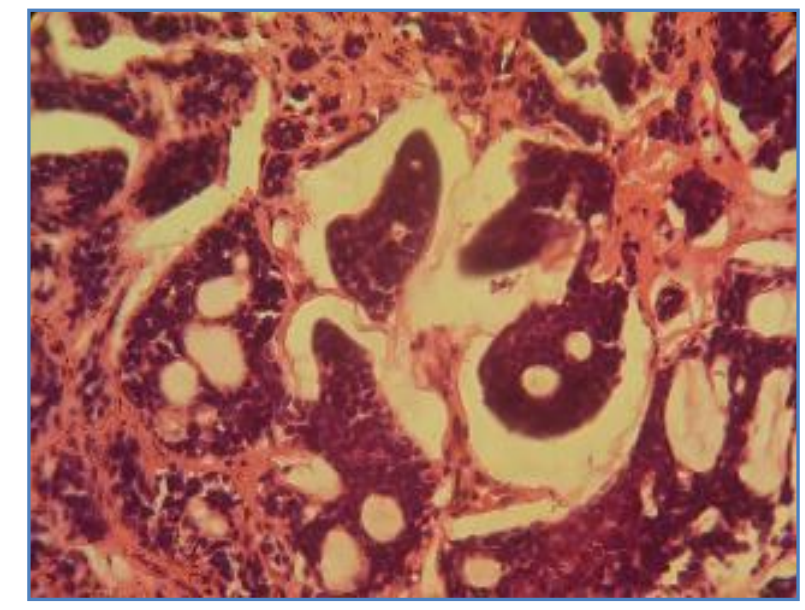

Fig. 2: Tumor cells with adenoid (tubular) pattern with central cystic space H \& E X 400

\section{REFERENCES:}

1. Stell PM. Adenoid cystic carcinoma. Clin Otolaryngol. 1986, 11: 267-291.

2. Patrick J. Bradley "Adenoid cystic carcinoma of the head and neck: a review" Curr Opin Otolaryngol Head Neck Surg. 2004, 12: 127-132.

3. Spies JW. Adenoid cystic carcinoma. Arch Surg. 1930, 21: 365-404.

4. Howard DJ, Lund VJ. Reflections on the management of adenoid cystic carcinoma of the nasal cavity and paranasal sinuses. Otolaryngol Head Neck Surg 1985, 93: 338-341.

5. Prokopakis EP, Snyderman CH, Hanna EY, et al. Risk factors for local recurrence of adenoidcystic carcinoma: the role of postoperative radiation therapy. Am J Otolaryngol. 1999, 20: 281-86.

6. Matsuba HM, Spector GJ, Thawley SE, et al. Adenoid cystic salivary gland carcinoma: a histologic review of treatment failure patterns. Cancer 1986, 57: 519-524.

7. Lee N, Millender LE, Larson DA, et al. Gamma knife radiosurgery for recurrent salivary gland malignancies involving the base of skull. Head Neck 2003, 25: 210-216.

8. Kim GE, Park HC, Keum KC, Lee CG, Suh CO, Hur WJ, Kim KM, Hong WP. “Adenoid cystic carcinoma of the maxillary antrum",Am J Otolaryngol. 1999, 20(2): 77-84.

9. Spiro RH, Huvos AG: Stage means more than grade in adenoid cystic carcinoma. Am J Surg. 1992, 164: 623-628.

10. Westra WH. The surgical pathology of salivary gland neoplasms. Otolaryngol Clin North Am. 1999, 39: 919-943. 


\section{AUTHORS:}

1. Shalini S. S.

2. Venkateswarlu V.

3. Prasad K. R. K.

4. Anitha S.

5. L. Veena Kumari

\section{PARTICULARS OF CONTRIBUTORS:}

1. Assistant Professor, Department of ENT, Mallareddy Medical College for Women, Suraram, RR District, Telangana.

2. Professor, Department of ENT, Mallareddy Medical College for Women, Suraram, RR District, Telangana.

3. Professor, Department of Pathology, Mallareddy Medical College for Women, Suraram, RR District, Telangana.

FINANCIAL OR OTHER COMPETING INTERESTS: None
4. Assistant Professor, Department of Pathology, Mallareddy Medical College for Women, Suraram, RR District, Telangana.

5. Professor, Department of Pathology, Mallareddy Medical College for Women, Suraram, RR District, Telangana.

\section{NAME ADDRESS EMAIL ID OF THE CORRESPONDING AUTHOR:}

Dr. Shalini S. S,

Assistant Professor, Department of ENT, Mallareddy Medical College for Women, Suraram-500055, RR District, Telangana. E-mail: sisodiashalini@gmail.com

Date of Submission: 15/06/2015. Date of Peer Review: 16/06/2015. Date of Acceptance: 01/07/2015. Date of Publishing: 08/07/2015. 